\title{
BIBLIOGRAFÍA DE ANTONIO ALATORRE
}

\section{LIBROS}

Las "Heroidas" de Ovidio y su huella en las letras españolas. Trad., introd. y notas. - Imprenta Universitaria, México, 1950. $96 \mathrm{pp}$.

Los 1,001 años de la lengua española. Pról. J. Guillén. — Studio Beatrice Trueblood-Bancomer, México, 1979. 372 pp.

Los 1,001 años de la lengua española. $2^{\mathrm{a}}$ ed. corr. y aum. El Colegio de México-F.C.E., México, 1989. 342 pp. [3ª ed., 2002]. Ensayos sobre crítica literaria. - Conaculta, México, 1993. 188 pp. El apogeo el castellano. - F.C.E., México, 1996. 80 pp. [reimpr. 2001].

Los 1,001 años de la lengua española. Secretaría de Educación Pública, México, 1998. [Edición especial destinada a profesores de segunda enseñanza].

Serafina y sor Juana (con tres apéndices) [en colaboración con Martha Lilia Tenorio]. - El Colegio de México, México, 1998. $150 \mathrm{pp}$.

El brujo de Autlán. — Aldus, México, 2001. 211 pp. [2a ed. 2010]. Fiori di sonetti/ Flores de sonetos. Antología bilingüe. Presentación y notas de... - El Colegio Nacional-Paréntesis-Aldvs, México, 2001. xxxvii +180 pp. [ $2^{\text {a }}$ ed. corr. y aum. - El Colegio de México-Aldvs, México, 2009].

El sueño erótico en la poesía española de los Siglos de Oro. — F.C.E., México, 2003. 197 pp.

Cuatro ensayos sobre arte poética. - El Colegio de México, México, 2007. 483 pp.

Sor Juana a través de los siglos. — El Colegio Nacional-El Colegio de México-UNAM, México, 2007. 2 ts. 
El heliocentrismo en el mundo de habla española. - F.C.E., México, 2011. 87 pp.

\section{Novela}

La migraña, F.C.E., México, 2012. 96 pp.

\section{Traducciones}

Rousseaux, André, "La poética de Paul Valéry". — Pan, 1945, núm. 3, 1-3.

Maritain, Raïssa, "Algunos músicos". - Pan, 1945, núm. 1, 6-8. Valéry, Paul, "Carta de un amigo". — Pan, 1945, núm. 5, 1-7.

George Duhamel, "El despojo". — Pan, 1946, núm. 7, Suplemento, $11 \mathrm{pp}$.

Cicely V. Wedgwood, Guillermo el Taciturno: Guillermo de Nassau, Príncipe de Orange, 1533-1584 [en colaboración con Joaquín Díez Canedo]. - F.C.E., México, 1947, 367 pp.

Howard C. Warren, Diccionario de psicología [en colaboración con Eugenio Imaz y Luis Alaminos]. - F.C.E., México, 1948, xvi + 383 pp. [3 ${ }^{\text {a }}$ ed. 1998].

Marcel Bataillon, Erasmo y España: estudios sobre la historia espiritual del siglo XVI. - F.C.E., México, 1950. 2 ts.: 923 pp. [2 ed. corr. y aum., Madrid, 1976].

Ovidio, Heroidas. Introd., trad. y notas... - UNAM, México, 1950. $461 \mathrm{pp}$.

Albert Béguin, El alma romántica y el sueño: ensayos sobre el romanticismo alemán y la poesía francesa. Trad. de M. Monteforte Toledo. Rev. por Margit Frenk y A.A. - F.C.E., México, 1951. 500 pp. [reimpr. 1996].

Joaquín María Machado de Assis, Memorias póstumas de Blas Cubas. Introd. de Lucía Miguel Pereira. - F.C.E., México, 1951. 242 pp. [3 ${ }^{\mathrm{a}}$ ed. 2006].

Samuel Eliot Morison, Historia de los Estados Unidos. Trads. Odón Durán y Faustino Ballvé. Rev. por...-F.C.E., México, 1951.3 ts. [4a ed. 1999].

Edward Sapir, El lenguaje. Introducción al estudio del habla [en colaboración con Margit Frenk]. — F.C.E., México, 1954, 280 pp. [reimpr. 2010]. 
Gilbert Highet, La tradición clásica: influencias griegas y romanas en la literatura occidental. — F.C.E., México, 1954. 449 pp. [reimpr. 1996].

José Pereira da Graça Aranha, Canaán. Introd., trad. y notas... — F.C.E., México, 1954. 266 pp.

Ernest Robert Curtius, Literatura europea y Edad Media latina [en colaboración con Margit Frenk]. — F.C.E., México, 1955. 2 ts. [reimpr. 2004].

François Chevalier, La formación de los latifundios en México: haciendas y sociedad en los siglos XVI y XVII. — F.C.E., México, 1956. 510 pp. [3 ${ }^{\text {a }}$ ed. 1999].

Jean Sarrailh, La España ilustrada de la segunda mitad del siglo XVIII. — F.C.E., México, 1957. 784 pp. [reimpr. 1981].

José Honório Rodrigues, Historiografía del Brasil, siglo XVI. Instituto Panamericano de Geografía e Historia, México, 1957, 102 pp.

RobertEscarpit, Contracorrientesmexicanas.-Porrúa,México, 1957.

Robin H. Humphreys, William Robertson y su "Historia de América". - Instituto Panamericano de Geografía e Historia, México, 1958.

Antonello Gerbi, La disputa del Nuevo Mundo: historia de una polémica, 1750-1900. - F.C.E., México, 1960. 885 pp. [2ª ed. 1993].

Silvio Zavala y Max Savalle, Programa de historia de América en la época colonial. - Instituto Panamericano de Geografía e Historia, México, 1961.

José Honório Rodrigues, Historiografía del Brasil, siglo XVII. Instituto Panamericano de Geografía e Historia, México, 1963, $261 \mathrm{pp}$.

Joaquín María Machado de Assis, Memorias póstumas de Blas Cubas. - Casa de las Américas, La Habana, 1964. 429 pp.

"Dos Mimos de Herondas". - Correspondencias, México, 1966, núm. 1.

"Los amoríos de Méroe, del Asno de oro de Apuleyo". - RUMex, 1974, abril.

Jacques Lacan, De la psicosis paranoica en su relación con la personalidad: seguido de primeros escritos sobre la paranoia. - Siglo XXI Editores, México, 1976. 353 pp.

Avelino Rodrigues, Portugal en revolución. - Siglo XXI Editores, México, 1977. 268 pp.

Antonello Gerbi, La naturaleza de las Indias nuevas. De Cristóbal Colón a Gonzalo Fernández de Oviedo. — F.C.E., México, 1978. 563 pp. [reimpr. 1993]. 
Paulo Freire, Cartas a Guinea-Bissau: Apuntes de una experiencia pedagógica en proceso. - Siglo XXI Editores, Madrid, 1978. 238 pp. [reimpr. 2003].

Joaquín María Machado de Assis, Memorias póstumas de Blas Cubas. Pról. de Juan Rulfo. - Secretaría de Educación Pública-UNAM, México, 1982. 207 pp.

George H. Williams, La Reforma radical. — F.C.E., México, 1983. $1017 \mathrm{pp}$.

Ovidio, Heroidas. Pról. y notas... - Secretaría de Educación Pública, México, 1987. 164 pp.

Williard F. King, Juan Ruiz de Alarcón, letrado y dramaturgo. Su mundo mexicano y español. - El Colegio de México, México, 1989.

"Yugurta de Arthur Rimbaud". - Biblioteca de México, 1992-93, núms. 6/7, 55-56.

\section{EDICIONES}

Raimundo Lida, Estudios hispánicos. Pról. de C. Blanco Aguinaga. - El Colegio de México, México, 1988. 322 pp.

Amado Nervo, Juana de Asbaje. Ed., introd y notas... - Conaculta, México, 1994.

Sor Juana Inés de la Cruz, Enigmas ofrecidos a la Casa del Placer. Ed. y estudio...-El Colegio de México, México, 1994. 173 pp. [2 $2^{\text {a }}$ ed., 1996].

Sor Juana Inés de la Cruz, Enigmas ofrecidos a la Casa del Placer. Ed. y pról... - El Colegio de México, México, 1995. [Edición de lujo, para biliófilos].

Fray Luis de León, Nueve Odas (y algo más). Sel., est. y notas... Universidad Autónoma Metropolitana, México, 1999.

Luis de Góngora, Soledades, ed. de Antonio Carreira; Sor Juana Inés de la Cruz, Primero sueño, ed. de A.A. - F.C.E., México, 2009. 155 pp.

Sor Juana Inés de la Cruz, Obras completas. T. 1: Lírica personal. $2^{\mathrm{a}}$ ed. Ed., introd. y notas... - F.C.E., México, 2009. xlii + 557 pp.

\section{Artículos}

"Ediciones de clásicos. (Sobre la Bibliotheca Scriptorum Graecorum et Romanorum Mexicana)". — CuA, 1949, núm. 3, 220-231. 
"Sobre traducciones castellanas de las Heroidas". - NRFH, 3 (1949), 162-166.

"Actualidad de los clásicos". - México en la Cultura, suplemento cultural de Novedades, México, 28 de diciembre de 1952.

"Graça Aranha, novelista y pensador". - CuA, 1953, núm. 6, 259-274.

"Quevedo, Erasmo y el doctor Constantino". - NRFH, 7 (1953), 673-685.

"Literatura clásica y literatura moderna". - UMx, 8 (1954), núm. 11.

"La crítica literaria". - RML, 1 (1955), núm. 2, 156-163.

"Los libros de México en el siglo xvi" - CuA, 1955, núm. 1, 219-226.

"El idioma de los mexicanos". - UMx, 10 (1955-56), núm. 2, pp. 1-2, 11-15 y 3, pp. 7-13.

"Breve historia de un problema: la mexicanidad de Ruiz de Alarcón". - Antología MCC. Mexico City College, México, 1956, pp. 241-259.

"Los romances de Hero y Leandro". - Libro jubilar de Alfonso Reyes. UNAM, México, 1956, pp. 1-41.

"Lope y Calderón en México: 1641". — HMx, 7 (1957), 237-238.

"Menéndez Pelayo, problema histórico". - CuA, 1957, núm. 1, 182-197.

"En torno a creación y tradición". — CuA, 1958, núm. 100, 462-475.

"Sobre nuestra realidad histórica. (Nota sobre Américo Castro, Iberoamérica: su historia y su cultura)". — HMx, 8 (1958), 132-134.

"Literatura de la emigración republicana española en México". - Boletín Bibliográfico de la Unión de Intelectuales Españoles, julio-octubre, 1959.

"Literatura de la emigración republicana española en México".Comparative Literature: Proceedings of the Second Congress of Comparative Literature. Chapel Hill, N.C., 1960, t. 2, pp. 606-614.

"Algunas notas sobre la Misa de amores de Juan de Dueñas". NRFH, 14 (1960), 325-328.

"México, 1808-1821: algunas aportaciones históricas". - $H M x$, 9 (1960), 586-600. [Firmado con el pseudónimo Carlos Olmedilla].

"Fortuna varia de un chiste gongorino". - NRFH, 15 (1961), 483-504.

"Juan José Arreola". - Cuaderno adjunto al disco antológico dedicado a Confabulario en la colección Voz viva de México, núm. 12, UNAM, México, 1961. 
"Dido y su defensa: Traductores españoles y portugueses de dos epigramas atribuidos a Ausonio". - Fil, 8 (1962), 307-323.

"María Rosa Lida de Malkiel (1910-1962)". — NRFH, 16 (1962), p. 632.

"María Rosa Lida in memoriam". — La Gaceta del F.C.E., México, 1962, núms. 99/100.

"Garcilaso, Herrera, Prete Jacopín y don Tomás Tamayo de Vargas". - MLN, 78 (1963), 126-151.

"Nota (prescindible) a unos sonetos de sor Juana". — El Rehilete, 1964, núm. 11, 45-56.

"Para la historia de un problema: la mexicanidad de Ruiz de Alarcón”. - ALM, 4 (1964), 161-202.

"León Felipe, poeta bíblico". - Folleto de presentación del disco de León Felipe, en la colección Voz viva de México, UNAM, 1965.

"Sobre el Responso a Verlaine de Rubén Darío". — Diálogos, 3 (1967), núm. 2, 4-5.

"El mexicano y su lengua. Algunas consideraciones antimetafísicas". - UMx, 22 (1967-68), núm. 10, 1-8.

"Características del español hablado en México". - Características de la cultura nacional. Ed. Leopoldo Zea, UNAM, México, 1969, pp. 75-88.

"El mexicano y su lengua". - Éve-Marie Fell y Claude Fell, Explicación de México. Armand Colin, Paris, 1969, 45-46.

"Alfonso Reyes y El Colegio de México". — Diálogos, 6 (1970), núm. 2, 28-29.

"Sobre el texto original de las Rimas de Gustavo Adolfo Bécquer. (A propósito de la edición de J.P. Díaz)". - NRFH, 19 (1970), 401-417.

"Una imagen de don Daniel Cosío Villegas". - Extremos de México. (Volumen de homenaje). El Colegio de México, México, 1971, pp. 1-4.

"Breve historia de un problema: la mexicanidad de Ruiz de Alarcón". - Critical Essays on the life and work of Juan Ruiz de Alarcón. Ed. James A. Par, Editorial Dos Continentes, Madrid, 1972, pp. 11-43 y 263-276.

"De folklore infantil". — Artes de México, 1973, núm. 162, 35-60.

"Eneas en el infierno". - UMx, 27 (1973), núm. 11, 1-8.

“Qué es la crítica literaria?”. - UMx, 27 (1973), núm. 9, 1-7.

"Alfonso Reyes. Pequeña crónica desmitificante". - Diálogos, 1974, núm. 58, p. 20.

"Garcilaso, Herrera, Prete Jacopín y don Tomás Tamayo de Vargas". - La poesía de Garcilaso. Ed. Elías L. Rivers, Ariel, Madrid, 1974, pp. 323-365. 
"Sobre la «gran fortuna» de un soneto de Garcilaso". - NRFH, 24 (1975), 142-177.

"Avatares barrocos del romance. (De Góngora a sor Juana Inés de la Cruz)". - NRFH, 26 (1977), 341-459.

"El español de México". - Educación, 1977, núm. 1, 3-13.

"Notas musicales en torno a Oviedo y a la casa real de Nápoles". - Antonello Gerbi, La naturaleza de las Indias nuevas, F.C.E., México, 1978, pp. 479-497.

"Para la historia de la tipografía griega en España". - RLC, 52 (1978), 233-244.

"Curriculum vitae". - Jesús Silva Herzog, Biografías de amigos y conocidos. Ed. de Cuadernos Americanos, México, 1979, pp. 18-22.

"In memoriam Raimundo Lida (1908-1979)". — NRFH, 29 (1980), p. 245.

"La Epistola moral a Fabio de Andrés Fernández de Andrada". Vuelta, 1980, núm. 45, 36-37.

"Para leer la Fama y Obras pósthumas de sor Juana Inés de la Cruz". - NRFH, 29 (1980), 428-508.

"Crítica literaria tradicional y crítica neo-académica". RUMex, diciembre, 1981, núm. 8, 6-13.

"Curriculum vitae" y "Discurso de ingreso al Colegio Nacional". - Memoria de El Colegio Nacional, México, 1981, núm. 4, pp. 151-164 y 169-189.

"Réplica [de Jorge Ibargüengoitia] y contrarréplica [de A. Alatorre]”. - Vuelta, 1982, núm. 71, 48-52.

"Alfonso Reyes a dos voces" (con Jaime García Terrés). - Sábado, suplemento de Uno más Uno, 13 de agosto de 1983, pp. 1, 2.

"En torno al concepto de literatura nacional". — Diálogos, 1983, núm. 110, 6-10.

"Crítica de la crítica". - CdelT, 1984, núm. 45, 2-8.

"De poética barroca hispano-portuguesa (con un ejemplo: el soneto en eco)". - BdF, 29 (1984), núm. 2, 235-271.

"El contrato entre autor y editor: un texto de Juan Vázquez del Mármol". — La Gaceta del F.C.E., 1984, núm. 165, 31-33.

"Literatura nacional". - La cultura nacional, México, 1984, pp. 65-71.

"Sobre Raimundo Lida". - NRFH, 33 (1984), anexo del núm. 2 (Homenaje a Raimundo Lida).

"Un soneto desconocido de sor Juana". - Vuelta, 1984, núm. 94, 4-13. 
"El Entremés de los tamalitos y otras perlas del Cancionero de Pancho Martínez". - México en el Arte, 1985, núm. 8, 13-22.

"Nebrija y la comunicación verbal en la conquista de América”. - El País, Madrid, 12 de octubre de 1985, suplemento extraordinario.

"Para la historia de la cultura provinciana: la revista Pan (1945)". - Vuelta, 1985, núm. 104, 48-54.

"Presentación". - Pan. Ed. facs. F.C.E., México, 1985, pp. 219238.

"Un devoto de sor Juana: Francisco Álvarez de Velasco". — Fil, 20 (1985), núm. 2, 157-176.

"Introducción" a Casa Santa (fotografías de Rafael Doniz). F.C.E., México, 1986, pp. 7-16.

"Sor Juana y los hombres". - Estudios, 1986, núm. 7, 7-27.

"Contra el nacionalismo: corrupción de la nacionalidad". - La Cultura en México, suplemento de Siempre!, 28 de enero de 1987.

"La Carta de sor Juana al P. Núñez (1682)". — NRFH, 35 (1987), 591-673.

"Sor Juana Inés de la Cruz y su «sueño» cumplido". — Spanish and Portuguese Distinguished Lecture Series, Colorado, 1987, núms. 1/2, pp. 11-27.

"Fama española de un soneto de Sannazaro". - NRFH, 36 (1988), 955-973.

"Lingüística y literatura". - Vuelta, 1988, núms. 133/134, 21-27.

"Lingüística y literatura (polémica)". — Sábado, suplemento de Uno más Uno, 20 de febrero y 12 de marzo de 1988.

"Palabras en los 40 años de la creación del Centro de Estudios Lingüísticos y Literarios de El Colegio de México". - Boletín Editorial de El Colegio de México, 1988, núm. 19, 21-26.

"Quevedo: de la silva al ovillejo". - Homenaje a Eugenio Asensio. Gredos, Madrid, 1988, pp. 19-31.

"Consideraciones sobre el arte de traducir". - Lenguaje y tradición en México. Ed. Herón Pérez Martínez, El Colegio de Michoacán, Zamora, 1989, pp. 391-402.

"Diálogo con Juan José Arreola sobre Juan Rulfo" ["Antonio, dinos de qué se trata. Lo mentiroso que era Rulfo, Juan José"], Diálogo con Juan José Arreola y con Armando Ponce ["¿Te acuerdas de Rulfo, Juan José Arreola?"] y "Los inventos de Rulfo". - Homenaje a Juan Rulfo. Ed. Dante Medina, Universidad de Guadalajara, Guadalajara, 1989, pp. 143-156, 197-209, 253-258. 
"Sobre la Noche oscura de san Juan de la Cruz". - La Gaceta del F.C.E., México, 1989, núm. 228, 15-21.

"Sor Juana y los hombres". - Temas de historia mexiquense. Ed. M. T. Jarquín, El Colegio Mexiquense, Toluca, 1989, pp. 131-157.

"Un momento en la vida de Alfonso Reyes (y una poesía suya inédita)". — La Gaceta del F.C.E., México, 1989, núm. 220, 6-15.

"Algo más sobre sor Juana y La segunda Celestina". — Proceso, México, 9 de julio de 1990, núm. 714, 56-57.

"Cómo escribí Los 1,001 años de la lengua española". - Textual, Universidad Autónoma de Chapingo, 1990, núm. 17.

"Consideraciones sobre el arte de traducir (extracto)". - Vuelta, 1990, núm. 163.

"Diálogo con Juan José Arreola". — Boletín Editorial de El Colegio de México, 1990, núm. 32.

"El aprendizaje teatral de sor Juana". — Proceso, México, 11 de junio de 1990, núm. 710, 50-53.

"El Nuevo Mundo". - Boletín Editorial de El Colegio de México, 1990, núm. 30, 3-9.

"La segunda Celestina de Agustín de Salazar y Torres. Ejercicio de crítica". - Vuelta, 1990, núm. 169, 46-52.

"Nada ocurre, poesía pura" (sobre Muerte sin fin de José Gorostiza). - Biblioteca de México, 1990, núm. 0, 6-8. [También en el núm. 1 de 1991].

"Octavio Paz y Poesía en Voz Alta". - Textual, Universidad Autónoma de Chapingo, 1990, núm. 20.

"Perduración del «ovillejo cervantino»". - NRFH, 38 (1990), 643-674.

"Testimonio de Antonio Alatorre" - Clara E. Lida y José A. Matesans, El Colegio de México: una hazaña cultural, 1940-1962. El Colegio de México, México, 1990, pp. 242-268, 275-280.

"Un momento en la vida de Alfonso Reyes (y una poesía suya inédita)". - Voces para un retrato. Ensayos sobre Alfonso Reyes. Ed. Víctor Díaz Arciniega, F.C.E.-Universidad Autónoma Metropolitana, México, 1990, pp. 11-24.

"Un soneto de Góngora". - Estudios, 1990, núm. 21, 7-34.

"Apelación (en torno a La segunda Celestina)". - Vuelta, 1991, núm. 170, p. 169.

"Diálogo con Juan José Arreola". — La Gaceta del F.C.E., México, 1991, núm. 242, 19-24.

"Emma Susana Speratti Piñero (1919-1990)". — NRFH, 39 (1991), 657-664. 
"Homenaje a Pedro Mártir de Anglería". - Memoria de El Colegio Nacional, México, 1991, pp. 45-60.

"La popularidad de una letrilla de Góngora". - ALM, 29 (1991), 17-40.

"Sor Juana: un Oráculo falso y unos Enigmas auténticos". - Proceso, 4 de febrero de 1991, núm. 744, 58-59.

"Sor Juana otra vez". - Proceso, 18 de febrero de 1991, núm. $746,56-57$.

"Tercer repaso a La segunda Celestina". - Proceso, 7 de enero de 1991, núm. 740, 57-58.

"Andanzas de Venus y Cupido en tiempos del Romancero nuevo". - Estudios de folklore y literatura dedicados a Mercedes Díaz Roig. Eds. B. Garza Cuarón e Y. Jiménez de Báez, El Colegio de México, México, 1992, pp. 337-390.

"Contra el nacionalismo: corrupción de la nacionalidad". $-E l$ nacionalismo en México. (VIII Coloquio de Antropología e Historia Regionales). Ed. Cecilia Noriega Elío, El Colegio de Michoacán, Zamora, 1992, pp. 19-26.

"Cuitas del joven Rulfo, burócrata". - Umbral, Guadalajara, 1992, núm. 2, 58-71.

"Efraín Huerta, Los hombres del alba". - Biblioteca de México, 1992, núm. 9, 56-57.

"Historia de la palabra gachupin". - Scripta philologica in honorem Juan M. Lope Blanch. Ed. E. Luna Traill, UNAM, México, 1992, t. 2, pp. 275-302.

"Pedro Mártir y el Nuevo Orbe". - Reflexiones lingüísticas y literarias. Eds. R. Olea Franco y J. Valender, El Colegio de México, México, 1992, t. 2, pp. 67-85.

"Egohistoria". - Egohistorias. El amor a Clío. Ed. J. Meyer, Centre d'Études Mexicaines et Centaméricaines, México, 1993, pp. 13-55.

"Homenaje a Pedro Mártir de Anglería". - Raíces indígenas, presencia hispánica. Ed. Miguel León Portilla, El Colegio Nacional, México, 1993, pp. 339-359.

"La fábula burlesca de Cristo y la Magdalena, de Miguel de Barrios". - NRFH, 41 (1993), 401-458.

"Lectura del Primero Sueño". - "Y diversa de mi misma / entre vuestras plumas ando": Homenaje a sor Juana Inés de la Cruz. Ed. S. Poot Herrera, El Colegio de México, México, 1993, pp. 101-126.

"Menéndez Pelayo y los poetas mexicanos: una escaramuza crítica”. - Raíces indígenas, presencia hispánica. Ed. Miguel 
León Portilla, El Colegio Nacional, México, 1993, pp. 435446.

"Avances en el conocimiento de sor Juana". - Conquista y contraconquista: la escritura del Nuevo Mundo. Eds. Julio Ortega y José Amor y Vázquez, El Colegio de México-Brown University, México, 1994, pp. 659-667.

"En defensa de Cabrera Infante". - Vuelta, 1994, núm. 206, p. 76.

"Entremés de los tamalitos de Fancisco Martínez". - Teatro mexicano, historia y dramaturgia. T. 10: Escenificaciones neoclásicas y populares (1797-1825). Ed. S. López Mena, Conaculta, México, 1994, pp. 63-65.

"Sor Juana y los hombres". - Debate Feminista, 1994, núm. 9, 329-348.

"Diálogo con Juan José Arreola". — Obras de Juan José Arreola. Ed. y pról. de Saúl Yurkievich, F.C.E., México, 1995, pp. 626-637.

"El desafío de un soneto en X". - Vuelta, 1995, núm. 222, 54-57.

"El Zurriago de Salazar y Castro contra el padre Calleja, amigo y biógrafo de sor Juana”. — LMM, 6 (1995), 343-366.

"Introducción" a sor Juana, Fama y Obras pósthumas, reimpr. facs. - UNAM, México, 1995, pp. ix-lxvii.

"Introducción" a la traducción al inglés del Primero sueño de sor Juana Inés de la Cruz por Gilbert Cunningham. — LMM, 6 (1995), 599-611.

"Invitación a la lectura del Sueño de sor Juana". - CuA, 1995, núm. 53, 11-33.

"La identidad del castellano en México". — Inti, 1995, núm. 42, 133-137.

"Notas al Primero sueño de sor Juana". — NRFH, 43 (1995), 379407.

"De nuevo sobre el texto de las Rimas de Bécquer". - NRFH, 44 (1996), 149-154.

"En torno a creación y tradición". - Conjuntos: teorías y enfoques literarios recientes. Ed. A. Vital, UNAM, México, 1996, pp. 393-405.

"Grata compañía [de Alfonso Reyes]". - Páginas sobre Alfonso Reyes. Ed. A. Rangel Guerra, Universidad Autónoma de Nuevo León, Monterrey, 1996, t. 2, pp. 20-23.

"Mirada de la memoria" (entevista con Roberto García Boni1la). — Los Universitarios, 1996, núm. 87, 12-15. 
"Notas sobre las Soledades. (A propósito de la edición de Robert Jammes)". - NRFH, 44 (1996), 57-97.

"Un aficionado de antaño (Luis Zapata y su Miscelánea)". Pauta, México, 1996, núms. 59/60, 8-16.

"Cairasco de Figueroa y los primeros tiempos del verso esdrújulo". - ALM, 35 (1997), 9-36.

"De nuevo sobre traducciones de las Heroidas de Ovidio". - Varia lingüistica y literaria: 50 años del CELL. Ed. M. E. Venier, El Colegio de México, México, 1997, t. 2, pp. 21-51.

"En torno a las silvas de Quevedo". — NRFH, 45 (1997), 129-135.

"La lengua española". - El patrimonio cultural de México. Ed. Enrique Florescano, F.C.E.-Conaculta, México, 1997. t. 1, pp. 281-306. [reimpr. 2004].

"La lengua española”. — Proceso, 6 de abril de 1997, núm. 1066, 52-53.

"Notas filológicas en torno a las poesías de Luis Martín de la Plaza". - NRFH, 45 (1997), 429-445.

"Arreola y yo". - El Búho, suplemento de Excélsior, México, 20 de septiembre de 1998.

"Comentario. (Sobre exequias de monarcas en el México colonial)". - México en fiesta. Ed. H. Pérez Martínez, El Colegio de Michoacán, Zamora, 1998, pp. 339-346.

"El texto de la Diana de Montemayor". - NRFH, 46 (1998), 407-418.

"Garcilaso y la amistad". — Estudios, 1998, núm. 54, 7-20.

"Juan José Arreola, el escritor-maestro de las letras mexicanas". - Tierra Adentro, Aguascalientes, 1998, 84-87.

"La persona de Juan Rulfo". - RCEH, 22 (1998), 165-177.

"La persona de Juan Rulfo". - LMM, 9 (1998), 370-386.

"Octavio Paz y la Poesía en Voz Alta". - El Semanario de Novedades, México, 27 de abril de 1998.

"Para la historia de la cultura literaria en Barcelona: el testimonio de Josep Vicens (1703)". — AFB, 21 (1998), 21-38.

"Una enfermedad contagiosa: las fantaseos sobre sor Juana" [en colaboración con Martha Lilia Tenorio]. - NRFH, 46 (1998), 105-121.

"Confesiones de un lector". - Juego de espejos. Homenaje a Jorge Luis Borges. El Colegio Nacional, México, 1999, pp. 7-19.

"Francisco de la Torre y su muy probable patria: Santa Fe de Bogotá". - NRFH, 47 (1999), 33-72.

"La persona de Juan Rulfo". — LMM, 10 (1999), 225-247 [reimpresión corregida de la de 1998]. 
"México, 1666: funerales de Felipe IV". - Memoria de El Colegio Nacional, México, 1999, pp. 41-50.

“Octavio Paz y yo". - Equis, 1999, núm. 11, 27-31.

"Perfil: Juan José Arreola". — Letras Libres, 1999, núm. 10, 84-87.

"Quevedo: labios en vez de párpados". - NRFH, 47 (1999), 369-383.

"Una imagen de don Daniel Cosío Villegas". - Cien años de Daniel Cosío Villegas. Clío-El Colegio Nacional, México, 1999, pp. 45-49.

"De Góngora, Lope y Quevedo". — NRFH, 48 (2000), 299-332.

"Del Cancionero de Pancho Martínez (1818)". — LMM, 11 (2000), 289-319.

"El Cancionero de Upsala". - Boletín Editorial de El Colegio de México, 2000, núm. 88, 2-10.

"El verso esdrújulo en el siglo xviı". - ALM, 38 (2000). 423445.

"Introducción" a Cancionero de Upsala. Ed. facs. — El Colegio de México, México, 2000.

"Prólogo" a Ernesto de Medina Lima, Crónicas de Autlán de la Grana. - Universidad de Guadalajara, 2000.

"Serafina y sor Juana: algunos puntos sobre las íes" [en colaboración con Martha Lilia Tenorio]. - Ibero, 2000, núm. 7, 90-94.

"Sobre el Aminta de Tasso traducido por Fabio Morábito". Paréntesis, 2000, núm. 3, 63-72.

"Un paréntesis lingüístico". - Paréntesis, 2000, núm. 2, 9-19.

"Afinidades: Cervantes y Góngora". - Homenaje a Carlos Orlando Nállim. Universidad Nacional del Cuyo, Mendoza, 2001, pp. 283-293.

"Avatares del verso alejandrino". - NRFH, 49 (2001), 363-407.

"Breve charla sobre el Diccionario". - Biblioteca de México, 2001, núms. 62/63, 41-44.

"Contra la superstición". - Letras Libres, 2001, núm. 31, 14-17.

"Crítica literaria tradicional y crítica neo-académica". - Ensayo literario mexicano. Sel. John. S. Brushwood. Ed. Federico Patán, UNAM-Universidad Veracruzana-Aldus, México, 2001, pp. 38-48.

"Cuatro siglos de actividad macarrónica en España". - Filología mexicana. Coords. Belem Clark de Lara y Fernando Curiel, UNAM, México, 2001, pp. 469-493.

"María Luisa y sor Juana". - Períodico de Poesía, 2001, núm. 2, 8-37. 
"Oficio: filólogo". - Paréntesis, 2001, núms. 9/10, 29-39.

"Palíndromos y retrógrados". - Paréntesis, 2001, núm. 12, 33-41.

"Sobre americanismos en general y mexicanismos en especial". - NRFH, 49 (2001), 1-51.

"Una enfermedad contagiosa: los fantaseos sobre sor Juana" [en la colaboración de Martha Lilia Tenorio]. - Visiones y revisiones. Memoria del Segundo Coloquio "Letras de la Nueva España”. Ed. José Quiñones Melgoza, UNAM, México, 2001, pp. 19-39.

"Antonio Alatorre y Juan José Arreola: un diálogo". - Boletín Editorial de El Colegio de México, 2002, núm. 95, 13-20.

"Arreola en la memoria". — La Tempestad, 2002, núm. 23, 9-14.

"Contra los denigradores de Lázaro de Tormes". - Encuentros en la diáspora: ensayos en honor de Carlos Blanco Aguinaga. Ed. Mari Paz Balibrea, GEXEL, Barcelona, 2002, pp. 137-149.

"Contra los denigradores de Lázaro de Tormes". - NRFH, 50 (2002), 427-455. [Versión muy ampliada].

"Diálogo con Juan José Arreola". — Gunther Stapenhorst, Juan José Arreola. Aldus, México, 2002, pp. 49-71.

"Diálogo con Juan José Arreola". - Boletín Editorial de El Colegio de México, 2002, núm. 95, 13-20. [Reimpresión del de 1990].

"El mundo al revés y la poesía española". — Paréntesis, 2002, núm. 16.

"Juan José Arreola, maravilla de rigor y expresividad poética". - Biblioteca de México, 2002, núms. 67/68, 2-5.

"Oficio: filólogo". - Una visión integradora: Universo, vida, hombre y sociedad. El Colegio Nacional, México, 2002, pp. 685701.

“¿Qué dice el Primero sueño?”. — La Tempestad, 2002, núm. 23, 37-46.

"San Juan de la Cruz y la música". — Pauta, 2002, núm. 81, 24-35.

"De cómo se alarman mientras yo me río. El español de México frente al inglés". - Letras Libres, 2003, núm. 53, 37-43.

"Fortuna varia de un chiste gongorino". - Antología conmemorativa. Nueva Revista de Filología Hispánica. El Colegio de México, México, 2003, t. 2, pp. 177-203.

"Hacia una edición crítica de sor Juana". - NRFH, 51 (2003), 493-526.

"Presentación" a Antología conmemorativa. Nueva Revista de Filología Hispánica. - El Colegio de México, México, 2003, pp. 9-13. 
"Un tema fecundo: las «encontradas correspondencias»". NRFH, 51 (2003), 81-146.

"Vida y milagros del grupo Alatorre". - Pauta, 2003, núm. 85, 12-31.

"El Lazarillo y Alfonso de Valdés". — NRFH, 52 (2004), 145-163.

"Encuentros cercanos con el politiqués". - Letras Libres, 2004, núm. 66, 28-29.

"Fortuna varia de un chiste gongorino". - Las sátiras de Quevedo y su recepción. Antología crítica virtual. Comp. Lía Schwartz, Centro Virtual Cervantes, Madrid, 2004.

"Más sobre sor Juana y los hombres". - Memoria del Primer Coloquio de Arte y Género. Instituto Nacional de las Mujeres, México, 2004, pp. 19-37.

"Nada ocurre, poesía pura". - Crítica sin fin: José Gorostiza y sus críticos. Ed. Álvaro Ruiz Abreu, Conaculta, México, 2004. pp. 173-179.

"Prólogo" a Escrituras de Frida Kahlo. Ed. Raquel Tibol. — Mondadori, México, 2004.

“Qué es la crítica literaria?” - Metodología de la crítica literaria. Selección de lecturas. Coord. Liliana Weinberg de Magis, UNAM, México, 2004.

"Sobre el P. Núñez, confesor de sor Juana (a propósito de dos libros recientes)". - LMM, 14 (2004), 7-22.

"Sor Juana Inés de la Cruz, americana poetisa". - El Español en el Mundo: Anuario del Instituto Cervantes, Madrid, 2004, $57-75$.

"La persona de Juan Rulfo". - CdelT, 2005, núm. 82, 45-52.

"Una Defensa del padre Vieira y un Discurso en defensa de sor Juana". - NRFH, 53 (2005), 67-96.

"Hacia una edición crítica de sor Juana. (Segunda parte)". NRFH, 54 (2006), 103-142.

"La alegría y la luz". - Boletín Editorial de El Colegio de México, 2006, núm. 119, 9-14. [Sobre Tomás Segovia].

"Las redondillas de sor Juana contra los «hombres necios»: un siglo de fama". - De amicitia et doctrina. Homenaje a Martha Elena Venier. Eds. Luis Fernando Lara, Reynaldo Yunuen Ortega y Martha Lilia Tenorio, El Colegio de México, México, 2007, pp. 45-76.

"Hacia una edición crítica de sor Juana. (Apéndice)". - NRFH, 57 (2009), 777-782.

"Dos antologías de poesía novohispana". - Boletín Editorial de El Colegio de México, 2010, núm. 145, 3-4. 
"En torno al Neptuno alegórico de sor Juana". — NRFH, 58 (2010), 269-278.

"La Casa de España en México, mi casa". - Los refugiados espanoles y la cultura mexicana. Actas de las Jornadas celebradas en España y México para conmemorar el septuagésimo aniversario de La Casa de España en México (1938-2008). Eds. James Valender y Gabriel Rojo, Residencia de Estudiantes-El Colegio de México, México, 2010, pp. 27-36.

"Presentación" a Poesía novohispana. Antología. Ed. Martha Lilia Tenorio. - El Colegio de México-Fundación para las Letras Mexicanas, México, 2010.

"De folklore infantil". - Boletín Editorial de El Colegio de México, 2011, núm. 150, 3-13. [Reimpresión del de 1973].

"La crítica literaria". - La Humildad Premiada, Universidad Autónoma de Coahuila, 2011, núm. 12, 29-33.

“Tiempo y poesía”. - Acta Poetica, 32 (2011), 19-87.

\section{RESEÑAS}

Sobre: Efraín Huerta, Los hombres del alba. — Pan, Jalisco, 1946, núm. 7, 39-45.

Sobre: Johannes Bühler, Vida y cultura en la Edad Media. - Filosofía y Letras, México, 12 (1946), 343-347.

Sobre: Alfonso Reyes, Grata compañia. - Suma Bibliográfica, México, 1948, núm. 10, 243-244.

Sobre: Bernabé Navarro, La introducción de la filosofía moderna en México. - RHA, 1948, núm. 26, 487-493.

Sobre: Onayda Alvarenga, Música popular brasileña. - CuA, 7 (1948), núm. 2, 279-283.

Sobre: Gilbert Highet, La tradición clásica, influencias griegas y romanas en la literatura occidental. - UMx, 8 (1953-54), núm. 11.

Sobre: Francisco Sanmartí Boncompte, Tácito en España (Barcelona, 1951). - NRFH, 9 (1955), 47-52.

Sobre: Hispanic Review, vol. 19. - NRFH, 9 (1955), 172-176.

Sobre: J. García Icazbalceta, Bibliografía mexicana del siglo XVI. CuA, 14 (1955), núm. 1, 219-226.

Sobre: Hispanic Review, vol. 20. — NRFH, 10 (1956), 234-238 [en colaboración con otros].

Sobre: Modern Language Notes, vols. 63-66. — NRFH, 10 (1956), 238-241. 
Sobre: Publications of the Modern Language Association of America, vols. 62 y 63. - NRFH, 10 (1956), p. 241.

Sobre: The Modern Language Review, vols. 45 a 47. - NRFH, 10 (1956), 465-469.

Sobre: Estudios dedicados a Menéndez Pidal (Madrid, 1950-1953) vols. 1 a 4. - NRFH, 11 (1957), 86-95 y 224-232 [en colaboración con otros; firmado también con las iniciales M.A.V. que corresponden a Marco Antonio Vergara].

Sobre: José María de Cossío, Fábulas mitológicas en España (Madrid, 1952). - NRFH, 11 (1957), 77-84.

Sobre: Kentucky Foreign Language Quarterly, vols. 1 y 2. - NRFH, 11 (1957), 238-239. [Firmado con las iniciales M.A.V. que corresponden a Marco Antonio Vergara].

Sobre: Romania, vols. 70 a 73. - NRFH, 11 (1957), 239-241 [en colaboración con J. M. Lope Blanch].

Sobre: Studies in Philology, vols. 45 a 49. - NRFH, 11 (1957), 235-237.

Sobre: Bulletin Hispanique, vols. 49 a 51. - NRFH, 12 (1958), 448-457 [en colaboración con Huberto Batis].

Sobre: Homenaje a Fritz Krüger (Mendoza, 1952). - NRFH, 12 (1958), 434-442 [en colaboración con otros].

Sobre: José C. Andrade, Horacio, poeta lírico: su influencia en la literatura castellana (Bogotá, 1956). — NRFH, 12 (1958), 443444.

Sobre: Joseph G. Fucilla, Relaciones hispanoitalianas (Madrid, 1953). - NRFH, 12 (1958), 414-416.

Sobre: Joseph G. Fucilla, Studies and notes (literary and historical) (Napoli-Roma, 1953). — NRFH, 12 (1958), 412-414.

Sobre: Lope de Vega, La Dorotea. Ed. de José Manuel Blecua (Madrid, 1955). - NRFH, 12 (1958), 419-422.

Sobre: Modern Language Quarterly, vols. 9 a 13. - NRFH, 12 (1958), 98 y 241-243.

Sobre: Philological Quarterly, vols. 27 a 31. - NRFH, 12 (1958), 468-469.

Sobre: Publications of the Modern Language Association of America, vols. 64 y 66. - NRFH, 12 (1958), 239-241.

Sobre: Symposium, vols. 1, 2 y 3. - NRFH, 12 (1958), 469-471.

Sobre: The Romanic Review, vols. 41 y 42. - NRFH, 12 (1958), 466-468 [firmado con las iniciales M.A.V. que corresponden a Marco Antonio Vergara].

Sobre: Arturo Farinelli, Poesía y crítica (temas hispánicos) (Madrid, 1954). - NRFH, 13 (1959), 145-146. [Firmado con 
las iniciales M.A.V. que corresponden a Marco Antonio Vergara].

Sobre: Convivium, vols. 16 al 20. - NRFH, 13 (1959), 405-407.

[Firmado con las iniciales M.A.V. que corresponden a Marco Antonio Vergara].

Sobre: Estudios dedicados a Menéndez Pidal (Madrid, 1954, 1956), vols. 5 y 6. - NRFH, 13 (1959), 133-140 [en colaboración con otros. Las iniciales M.T. corresponden a Marcos Torres, M.A.V. que corresponden a Marco Antonio Vergara].

Sobre: Joaquín de Entrambasaguas, Miscelánea erudita (Madrid, 1957). - NRFH, 13 (1959), 144-145. [Firmado con las iniciales M.A.V. que corresponden a Marco Antonio Vergara].

Sobre: Kenneth R. Scholberg, Pierre Bayle and Spain (Chapel Hill, 1958). - NRFH, 13 (1959), p. 395.

Sobre: Marcelino Menéndez Pelayo, Bibliografía hispano-latina clásica. Ed. E. Sánchez Reyes (Santander, 1950-1953). NRFH, 13 (1959), 115-123.

Sobre: Quaderni Ibero-Americani, vol. 2. - NRFH, 13 (1959), 164166. [Firmado con las iniciales M.A.V. que corresponden a Marco Antonio Vergara].

Sobre: Studies in Philology, vols. 50 y 51. - NRFH, 13 (1959), p. 405.

Sobre: Letterature Moderne, vols. 1 a 3. — NRFH, 13 (1959), 416-418.

Sobre: Agapito Rey (ed.), El libro de los cien capitulos (Bloomington, 1960). - NRFH, 14 (1960), 355-362.

Sobre: Alfonso Méndez Plancarte, Cuestiúnculas gongorinas (México, 1955). — NRFH, 14 (1960), 394-395.

Sobre: Antonio García Gutiérrez, El diablo nocturno. Ed. H. L. Johnson (México, 1956). — NRFH, 14 (1960), p. 397. [Firmado como M. A. Vergara].

Sobre: Cuadernos Americanos, ts. 8, 9 y 10. - NRFH, 14 (1960), 404-410. [Firmado con las iniciales M.A.V. que corresponden a Marco Antonio Vergara].

Sobre: Dámaso Alonso, Menéndez Pelayo, crítico literario. (Las palinodias de don Marcelino) (Madrid, 1956). — NRFH, 14 (1960), 396-397.

Sobre: Francisco Monterde, La literatura mexicana en la obra de Menéndez y Pelayo (México, 1958). — NRFH, 14 (1960), 369-373.

Sobre: J.F. Peeters Fontainas, L'officine espagnole de Martin Nutius à Anvers (Anvers). - NRFH, 14 (1960), 391-392. [Firmado como M. A. Vergara]. 
Sobre: Josefina Guevara Castañeira, Del Yunque a los Andes. (San Juan, 1959). - NRFH, 14 (1960), 145-146. [Firmado con las iniciales M.A.V. que corresponden a Marco Antonio Vergara].

Sobre: Kentucky Foreign Language Quarterly, vols. 3 a 5. - NRFH, 14 (1960), 410-412. [Firmado con las iniciales M.A.V. que corresponden a Marco Antonio Vergara].

Sobre: Lisardo Rubio y Virgilio Bejarano, Documenta ad linguae Latinae historiam inlustrandam (Madrid, 1955). - NRFH, 14 (1960), p. 383. [Firmado como M. Torres].

Sobre: Luis Díez del Corral, La función del mito clásico en la literatura contemporánea (Madrid, 1957). — NRFH, 14 (1960), 388-389.

Sobre: Miguel de la Pinta Llorente, Estudios y polémicas sobre fray Luis de León (Madrid, 1956). — NRFH, 14 (1960), 362-369. [Firmado como Marco Antonio Vergara].

Sobre: Pedro Sáinz Rodríguez, Menéndez Pelayo, historiador y crítico literario (Madrid, 1956). — NRFH, 14 (1960), 395-397.

Sobre: Ruth Kelso, Doctrine for the Lady of the Renaissance (Urbana, 1956). - NRFH, 14 (1960), 387-388. [Firmado como M. A. Vergara].

Sobre: Samuel Gili Gaya, Vox: Diccionario de sinónimos (Barcelona, 1958). — NRFH, 14 (1960), 349-353. [Firmado como Marcos Torres].

Sobre: Vicente Espinel, Diversas rimas. Ed. Dorothy C. Clarke (New York, 1956). - NRFH, 14 (1960), 393-394.

Sobre: Antonio Machado, "Los complementarios" y otras prosas póstumas. Ed. Guillermo de Torre (Buenos Aires, 1957). NRFH, 16 (1962), 480-481.

Sobre: Cuadernos Americanos, años 11 y 12. - NRFH, 16 (1962), 145-151. [Firmado con las iniciales M.A.V. que corresponden a Marco Antonio Vergara].

Sobre: Cultura Neolatina, vols. 9 a 12. — NRFH, 16 (1962), 163-165.

Sobre: Homenaje a J. A. van Praag. 1930-1935 (Amsterdam, [1956]). — NRFH, 16 (1962), 134-137.

Sobre: Les Lettres Romanes, vols. 5 a 8. — NRFH, 16 (1962), 139-141.

Sobre: Revista de Dialectología y Tradiciones Populares, vol. 13. NRFH, 16 (1962), 167-170. [Firmado con las iniciales M.T. que corresponden a Marcos Torres].

Sobre: Revue de Littérature Comparée, vols. 24 a 28. - NRFH, 16 (1962), 160-163.

Sobre: Symposium, vols. 4 a 8. - NRFH, 16 (1962), 142-145. 
Sobre: Studi in onore di Angelo Monteverdi (Modena, 1959). NRFH, 16 (1962), 132-134 [en colaboración con otros].

Sobre: Stanley L. Robe, Hispanic Riddles from Panama. Collected from Oral Tradition (Berkeley, 1963). - NRFH, 17 (1964), 421-422. [Firmado como M. A. Vergara].

Sobre: Carlos Alberto Moreyra, Los criptogramas de Santa Teresa (Córdoba, Argentina, 1964). — NRFH, 19 (1970), 155158.

Sobre: Carlos Fernández Shaw, Poesías completas. Ed. Melchor Fernández Almagro (Madrid, 1966). — NRFH, 19 (1970), p. 175. [Firmado como M. A. Vergara].

Sobre: Clara Louisa Penney, Printed Books: 1468-1700 in the Library of the Hispanic Society of America (New York, 1965). NRFH, 19 (1970), 418-420.

Sobre: Clara Louisa Penney, The Hispanic Society of America: An album of selected bookbindings (New York, 1967). — NRFH, 19 (1970), 420-421.

Sobre: Dorothy Petersen Ackerman, A Catalogue of the Talfourd P. Linn Collection of Cervantes Materials. - NRFH, 19 (1970), 171-172. [Firmado como M. A. Vergara].

Sobre: Bulletin Hispanique, vols. 54 a 56. - NRFH, 20 (1971), 179-185. [Firmado como M. A. Vergara].

Sobre: Comparative Literature, vols. 5 a 7. - NRFH, 20 (1971), 176-178. [Firmado como M. A. Vergara].

Sobre: Cultura Neolatina, vols. 13 a 19. - NRFH, 20 (1971), 169170. [Firmado como M. A. Vergara].

Sobre: Dinko Cvitanovic (ed.), El sueño y su representación en el Barroco español (Bahía Blanca, 1969). — NRFH, 20 (1971), 145-148.

Sobre: Les Lettres Romanes, vols. 12 a 16. - NRFH, 20 (1971), 170-172. [Firmado como M. A. Vergara].

Sobre: Modern Language Quarterly, vols. 14 a 20. - NRFH, 20 (1971), 173-174.

Sobre: Romance Philology, vols. 4 a 6. - NRFH, 20 (1971), 162167. [Firmado como M. A. Vergara].

Sobre: The Romanic Review, vols. 43-45. - NRFH, 20 (1971), 167169. [Firmado como M. A. Vergara].

Sobre: Publications of the Modern Language Association of America, vol. 69. - NRFH, 21 (1972), 152-153.

Sobre: The Romanic Review, vols. 46 a 52. - NRFH, 21 (1972), 146-147. 
Sobre: Carlos Monsiváis, A ustedes les consta. - Vuelta, 1981, núm. 53, 37-41.

Sobre: Jorge Ibargüengoitia, Los pasos de López. - Vuelta, 1982, núm. 69, 36-37.

Sobre: Nechama Kramer-Hellinx, Antonio Enríquez Gómez. Literatura y sociedad en "El siglo pitagórico y Vida de don Gregorio Guadaña" (New York, 1992). — NRFH, 44 (1996), 599-602.

Sobre: Pablo Cuevas Subías, La formación de Manuel de Salinas [y Linaza] en el Barroco oscense (Huesca, 1995). - NRFH, 44 (1996), 602-604.

Sobre: Augusto Guarino, La narrativa di Joan Timoneda (Napoli, 1993). - NRFH, 46 (1998), 133-137.

Sobre: Carajicomedia. Ed. e introd. de Álvaro Alonso (Archidona, Málaga, 1995). - NRFH, 46 (1998), 469-473.

Sobre: Nicolás Fernández de Moratín, Arte de putear. Ed. de Isabel Colón y Gaspar Garrote Bernal (Archidona, Málaga, 1995). - NRFH, 46 (1998), 484-495.

Sobre: Elías Trabulse, La muerte de sor Juana (México, 1999). NRFH, 47 (1999), 441-446.

Sobre: Hombres y letras del virreinato. Homenaje a Humberto Maldonado. Ed. J. Quiñones Melgoza y M. V. Jardón (México, 1995). - NRFH, 47 (1999), 171-176.

Sobre: Juan Bautista Corvera, Obra literaria. Ed. Sergio López Mena (México, 1995). - NRFH, 47 (1999), 171-176.

Sobre: Otto Vaenius, Quinti Horatii Flacci Emblemata. Introd. Paloma Fanconi Villar (Madrid, 1996). — NRFH, 47 (1999), $177-180$.

Sobre: Melchor de Santa Cruz, Floresta española. Ed. de M. Chevalier y M. P. Cuartero (Barcelona, 1997). - NRFH, 48 (2000), 144-146.

Sobre: José Lara Garrido, Relieves poéticos del Siglo de Oro. De los textos al contexto (Málaga, 1999). — NRFH, 49 (2001), 145151.

Sobre: Alberto Martino, Il "Lazarillo de Tormes" e la sua ricezione in Europa (1554-1753) (Pisa-Roma, 1999). - NRFH, 50 (2002), 252-264.

Sobre: Vicente Espinel, Diversas rimas [1591]. Ed. de Gaspar Garrote Bernal (Málaga, 2001). - NRFH, 50 (2002), 591-606.

Sobre: Margit Frenk, Nuevo Corpus de la antigua lírica popular hispánica (México, 2003). — NRFH, 51 (2003), 589-593.

Sobre: Agustín de Salazary Torres, Elegir alenemigo. Ed. T. Austin O'Connor (New York, 2002). - NRFH, 52 (2004), 207-213. 
Sobre: Agustín de Salazar y Torres, El amor más desgraciado, Céfalo y Pocris. Ed. T. Austin O'Connor (Kassel, 2003). NRFH, 53 (2005), 567-570.

Sobre: Alfonso de Valdés, La vida de Lazarillo de Tormes. Introd. de Rosa Navarro Durán. Ed. y notas de Milagros Rodríguez Cáceres. - Hoja por Hoja, México, 2007.

Sobre: Marcial Rubio Árquez, El Cancionero de Juan de Escobedo (ms. 330 Biblioteca Real Academia Española). Edición y estudio (Pisa, 2004). - NRFH, 55 (2007), 181-187.

Sobre: Cancionero autógrafo de Pedro de Padilla (manuscrito 1579 de la Biblioteca Real de Madrid). Ed. de José J. Labrador Herraiz y Ralph A. DiFranco (México, 2007). - NRFH, 57 (2009), 802-808.

Sobre: Pedro de Padilla, Thesoro de varias poesías [Madrid, 1580]. Ed. de José J. Labrador Herraiz y Ralph A. DiFranco (México, 2008). - NRFH, 57 (2009), 802-808. 